\title{
PUBLICIDADE, INSTITUCIONALIDADE E FORMAÇÃO PUBLICITÁRIA
}

\author{
Advertising, institutionality, and advertising education \\ Publicidad, institucionalidad y formación publicitaria
}

\author{
Rodrigo Stéfani Correa \\ Universidade Federal de Santa Maria, Rio Grande do Sul, Brasil. \\ Doutor em Comunicação e Semiótica pela Pontifícia Universidade Católica de São Paulo, atua \\ como professor adjunto na Universidade Federal de Santa Maria, onde aplica-se aos estudos e \\ pesquisas em duas áreas distintas: processos criativos e estudos de mercado. Mestre em Ciências \\ da Computação pela Universidade Federal de Santa Catarina e membro pesquisador do grupo \\ de pesquisa Publicidade nas Novas Mídias (CNPq/UFPE), com publicação do livro Propaganda \\ digital. Líder do grupo de pesquisa O Ensino e Aprendizagem de Criação Publicitária. Experiência \\ profissional nos campos de comunicação digital e linguagem publicitária multimídia. \\ E-mail: rodrigo.correa@ufsm.br
}

\begin{abstract}
Juliana Petermann
Universidade Federal de Santa Maria, Rio Grande do Sul, Brasil.

Doutora em Ciências da Comunicação pela Universidade do Vale do Rio dos Sinos, é professora no curso de Publicidade e Propaganda e no Programa de Pós-Graduação em Comunicação na Universidade Federal de Santa Maria. Atua principalmente nos seguintes temas: criação publicitária, ensino de criação publicitária, criatividade, marcas e seus discursos, estratégias de significação, análise de imagens publicitárias. Coordena o grupo Nós - Pesquisa Criativa. Recebeu o Troféu Reconhecimento da Associação Riograndense de Propaganda em 2014. Foi escolhida professora do ano, recebendo o Prêmio Destaque em Ensino na UFSM em 2017.

E-mail: jupetermann@yahoo.com.br
\end{abstract}

\section{Fábio Hansen}

Universidade Federal do Paraná, Paraná, Brasil. Doutor em Letras pela Universidade Federal do Rio Grande do Sul, é professor adjunto no Departamento de Comunicação Social e professor permanente no Programa de Pós-Graduação em Comunicação da Universidade Federal do Paraná. Atua na linha de pesquisa "comunicação e formações socioculturais", articulando suas investigações com grupos de pesquisa certificados no CNPq: Ensino Superior de Publicidade e Propaganda e Estudos sobre Comunicação, Consumo e Sociedade. Desenvolve pesquisas sobre criação publicitária, ensino e formação em publicidade e propaganda. Mestre em Educação, Administração e Comunicação pela Universidade São Marcos, graduado em Publicidade e Propaganda pela Universidade de Passo Fundo.

E-mail: fabiohansen@yahoo.com

RESUMO As reflexões apontadas neste artigo compreendem a primeira fase da pesquisa interinstitucional com a temática do ensino de criação publicitária e repercutem os trabalhos exercidos na Escola Superior de Propaganda e Marketing (RS), na Universidade Federal de Pernambuco (PE) e na Universidade Federal de Santa Maria (RS). O objetivo principal nesta etapa foi explorar as práticas de ensino consideradas institucionalizadas, fundamentais para compreensão de determinadas características pedagógicas favoráveis ao senso de "inovação" nas dinâmicas do ensino ligado às matérias de criatividade. Em

\section{Como citar este artigo:}

CORREA, R. S.; PETERMANN, J.; HANSEN, F. Publicidade, institucionalidade e formação publicitária.

Signos do Consumo, São Paulo, v. 10, n. 2, p. 38-52, jul./dez. 2018. 
especial, consideram-se as proposições teóricas de Piaget, Edgar Morin e Vygotsky quanto aos processos de orientação, em que se coloca em perspectiva três dimensões específicas: interação, técnicas e condições de ambiência, igualmente tencionadas pelas projeções de Berger e Luckmann e outros textos dos pesquisadores colaboradores, que farão um estudo longitudinal abarcando todas as regiões do Brasil, com exceção da região Norte.

PALAVRAS-CHAVE Publicidade, Criação, Pedagogia, Interação.

ABSTRACT Propositions set forth in this article encompass the first phase of the interinstitutional research project on the teaching of advertising and creation. They echo works developed with Escola Superior de Propaganda e Marketing (RS), Universidade Federal de Pernambuco (PE), and Universidade Federal de Santa Maria (RS). At this stage, the main goal was to explore those teaching practices deemed institutionalized, which are fundamental for the understanding of certain pedagogical characteristics that are favourable to a sense of 'innovation' in teaching dynamics related to issues of creativity. Theoretical inputs by Piaget, Edgar Morin, and Vygotsky are especially considered regarding guidance processes, in which three specific dimensions are put in place: interaction, techniques, and conditions of ambience, equally tensioned by Berger and Luckmann's projections as well as other texts by collaborating researchers, who have carried out a longitudinal study in every region of Brazil, but the North.

KEYWORDS Advertising, Creativity, Pedagogy, Interaction.

RESUMEN Las reflexiones apuntadas en este artículo comprenden la primera fase de la investigación interinstitucional con la temática de la enseñanza de creación publicitaria y repercuten los trabajos ejercidos junto a la Escuela Superior de Propaganda y Marketing (RS), Universidad Federal de Pernambuco (PE) y en la Universidad Federal de Santa Maria (RS). El principal objetivo en esta etapa fue explorar las prácticas de enseñanza consideradas institucionalizadas, fundamentales para la comprensión de determinadas características pedagógicas y favorables al sentido de "innovación” en las dinámicas de la enseñanza vinculadas a las materias de creatividad. En particular, se consideran las proposiciones teóricas de Piaget, Edgar Morin y Vygotsky frente a los procesos de orientación, en que se plantean en perspectiva tres dimensiones específicas: la interacción, las técnicas y las condiciones de ambientes, igualmente previstas por las proyecciones de Berger \& Luckmann y otros textos de los investigadores colaboradores, que harán un estudio longitudinal abarcando todas las regiones de Brasil, con excepción de la región Norte.

PALABRAS CLAVE Publicidad, Creatividad, Pedagogía, Interacción.

\section{APRESENTAÇÃO}

Pensar na pedagogia do ensino de publicidade, especialmente no que compete ao trabalho de identificar novas metodologias que tragam proposições inovadoras do campo da educação superior, remete o olhar para três grandes dimensões que sugerem um tipo de investigação mais detalhada, cabendo-nos empreender sobre a forma de praticar o ensino das disciplinas ligadas a área de criação publicitária.

A primeira dimensão pedagógica que nos coloca em cheque versa sobre a existência do conflito que reside na articulação do professor ao exercer o papel de mediador, sem ferir a autonomia do estudante, conforme defende Paulo Freire (1997) em seu clássico Pedagogia da autonomia; em perspectiva, tensionamos os questionamentos para o desafio de não se ausentar do processo criativo e dissolver a responsabilidade da criação publicitária com os alunos. A segunda dimensão, mais pragmática, questiona em quais condições técnicas os jovens estudantes de publicidade precisam do auxílio do professor para desenvolver suas potencialidades criativas em publicidade, uma vez que há uma grande interferência do conhecimento prático nesse campo de aprendizado (ambiência pragmática). À terceira e última dimensão coube refletir sob quais condições estruturais esse professor se encontra na sala 
de aula, tendo como consequência os recursos tecnológicos que estão à sua disposição, bem como a quantidade de alunos por turma e o tipo de atividades colaborativas que são desenvolvidas em grupo (técnicas), para seu melhor aproveitamento.

No campo teórico levam-se em consideração as proposições clássicas de Jean Piaget (PIAGET; INHELDER, 1986) na perspectiva em que o autor corrobora com o insight de que o conhecimento não nasce com o indivíduo, mas é o resultado da sua interação com o meio, que provoca novas descobertas para que ele se adapte cada vez melhor ao meio - conhecido como princípio da acomodação. A visão de Piaget nos conecta não apenas à lógica de Paulo Freire - orientando as observações para o campo da criação publicitária como um terreno dinâmico, no qual o indivíduo está sempre evoluindo intelectualmente, pois está sempre interagindo, assimilando e acomodando seu repertório de acordo com os desafios sugeridos ou provocados pela ação do professor -, mas também às questões aplicadas à ideia de reificação, que parece ser a chave central do construtivismo social.

A expressividade humana proporciona objetivações (a tradução para reificação), isto é, manifesta-se em produtos da atividade humana que estão ao dispor tanto dos produtores quanto dos outros homens, como elementos de um mundo em comum. (BERGER; LUCKMANN, 2001, p. 53)

Nesse sentido, Piaget (1977) defendia três conceitos fundamentais que foram apropriados pelas análises desta pesquisa, fruto de um trabalho fundamentado na metodologia longitudinal, de abrangência geográfica, no que concerne ao exercício e à tradução das práticas interpretativas na formação profissional do campo publicitário. São eles: interação, assimilação e acomodação. Piaget reforça a partir de seus ideais que o princípio da aquisição do conhecimento, referindo-se à "equilibração" (o desafio que surge do conhecimento anterior diante de novas situações), é uma condição necessária para que o indivíduo avance no desenvolvimento do saber; mas afirma também que só este fato não é suficiente. Acredita-se que é necessária uma ação de quem aprende e um esforço para que esse avanço aconteça, e que assim seja sucessivamente na evolução da inteligência.

Quanto à segunda dimensão das análises - na qual se referencia o auxílio dado pelo professor para desenvolver as potencialidades criativas de seus estudantes - cabe nos ampararmos nas reflexões de Edgar Morin (2001), nas quais o autor documentou pontos a serem melhorados e reeditados no sistema educacional francês para os três níveis de ensino (primário, secundário e ensino universitário). Morin enfatizou não somente a necessidade da "descompartimentação" do conhecimento e de uma reciclagem de saberes, a fim de que se tenha uma cabeça bem-feita ao invés de uma cabeça cheia - no sentido figurativo, cheia de inutilidades -, como também flexionou nosso olhar no sentido de obtermos uma consciência crítica a respeito do professor que trabalha com criatividade, o qual está sujeito ao sistema de ensino onde é impelido a querer transmitir de tudo um pouco, ao invés de se centralizar nas necessidades mais fundamentais e profundas, pautadas em necessidades de maior complexidade e focadas no aluno. Ao que tudo indica existe, de maneira institucionalizada nas escolas de ensino superior em publicidade, uma espécie de dever/tarefa de cumprir um repertório publicitário enrijecido pelo plano de aula docente, que muitas vezes não está compatível com o dinamismo das atitudes de criatividade referenciadas no próprio campo de atuação do publicitário. 
Como ancoragem dos procedimentos de análise, nesta etapa inicial de pesquisa, que de partida nos permitiram investigar as condições de aprendizagem em diferentes sistemas universitários no Brasil, consideramos ainda, do ponto de vista teórico, a visão de Lev Vygotsky (1989) quanto à função do ambiente social no desenvolvimento e na aprendizagem, como é o caso das macroestruturas que dependem do processo de abertura para um novo contexto de significados - razão pela qual o ensino se amplifica. Talvez esse ambiente social tenha contornos diferentes quando se relacionam as condições das instituições privadas com as das instituições públicas de ensino superior de publicidade. De qualquer forma, na medida do possível nos manteremos neutros nessa dicotomia até que existam subsídios mais concretos para contextualizá-los.

Portanto, quando Vygotsky nos possibilita validar certas concepções da intervenção escolar, pela ênfase no poder das mediações entre o sujeito e o objeto de conhecimento, inicia-se a crença de que o sistema de ensino é uma espécie de mecanismo essencial para o descobrimento do mundo e a construção de si mesmo.

\section{O ENSINO DE CRIAÇÃO PUBLICITÁRIA}

As abordagens sobre os desafios de ensinar criação publicitária ganham repercussão no campo teórico especialmente pelas proposições complementares que Dirceu Tavares (2012), Rodrigo Correa (2016) e Fábio Hansen (2013) avultaram em suas articulações de pesquisa, que merecem destaque para melhor posicionamento dos objetivos a que se destina nossa pesquisa.

Quando o professor se coloca entre a formação cultural do aluno e a necessidade de encontrar nessa formação subsídios que sejam importantes para promover associação de ideias, como gatilho para o processo criativo em publicidade, pode-se considerar que há uma proposição pedagógica importante que define a relação de aprendizagem. No entanto Dirceu Tavares (2012) salienta que muitas vezes o problema do trabalho pedagógico está na condição que o aluno iniciante apresenta, uma vez que esta é definida por um pequeno repertório de expressões publicitárias, de modo que, quando ele é estimulado a produzir diante de um briefing de trabalho cujo tema não fez parte de uma análise anterior de cases publicitários essa condição o induz a incorrer num segundo problema, que é a tentação de realizar criações como "fotografia do briefing" ou, como o próprio autor define no sentido figurado, "empacota e manda”.

"Fotografia do briefing”, ou "empacota e manda", são clichês publicitários. São fórmulas prontas que funcionam como chaves simbólicas fixas. Há um arsenal de truques, inventar uma cor padrão para um produto, mesmo não tendo adequação com a sua identidade física. Um animal escolhido aleatoriamente como mascote por ser exótico ou amoroso. Ou frases feitas: "entenda as vantagens de quem entende você", "as novidades de quem sempre inova", "loucuras de verão na maior queima de estoques”. (Ibidem, p. 2)

Além da condição técnica que o estudante de publicidade apresenta, segundo o autor, em sua fase inicial de formação, parece existir outro problema quanto aos estímulos criativos, para o qual Fabio Hansen (2013) chama atenção ao comprovar algo recorrente em sala de aula que configura a permanência de uma espécie de poder hegemônico das 
empresas de publicidade. Estas controlam o discurso pedagógico e afetam diretamente a produção acadêmica, a qual se torna refém desse processo e se presta ao papel de reproduzir os ecos institucionais desse mercado. Rodrigo Correa (2016) corrobora com as análises desse sistema, chamando atenção para um terceiro problema: muitos professores que se acomodam por conveniência na carreira docente da publicidade, sem possuir a necessária vocação, encontram na necessidade de ocultar certas deficiências pedagógicas um modelo de discurso que desqualifica o estudante, denigre o campo da profissão e distorce a realidade através de uma linguagem erudita e prolixa, uma vez que estamos à mercê de uma sociedade em profunda transformação e de uma liquidez total, especialmente do ponto de vista das tecnologias e da inovação.

É como se o professor dissesse: eu sou o professor e preciso materializar tal condição. Para tanto, recorre a uma formulação imaginária (elementar): a de que o mercado publicitário legitima seu dizer. Ao recorrer ao discurso profissional, apregoando sua sabedoria, o professor imagina apoderar-se de credibilidade, afirmando-se. Atuando ou não no mercado publicitário (em agências, anunciantes, veículos, fornecedores etc.), o professor presume que seu dizer terá maior respaldo ao se reportar ao mercado. Essa é uma das formações imaginárias que funcionam no discurso pedagógico de criação publicitária. (HANSEN, 2013, p. 469)

A crítica de Hansen possui uma colocação muito específica no sentido de que, ao invés de o professor centrar-se em procedimentos inovadores, lúdicos e adaptáveis às características de seus alunos, opta por reproduzir as técnicas tradicionais já estandardizadas no meio profissional, porque ao reproduzi-las o docente incorpora um tipo de capital simbólico que lhe confere confiança e coerência diante dos alunos. O reflexo dessa prática interfere no modelo homogeneizado de instrução profissional que os estudantes de publicidade recebem nas universidades e faculdades brasileiras.

Ao dimensionar o campo de investigação que recobre as análises do processo de ensino de criação publicitária, no que concerne aos problemas de área que foram destacados, torna-se inevitável pensar nas possíveis contribuições de uma nova área de investigação que, além de ampliar o campo de visão dos problemas descritos, também sugerisse novos apontamentos relativos ao desafio de ensinar criação publicitária.

\section{ESTRATÉGIAS METODOLÓGICAS}

Optamos por uma metodologia conjugada de trabalho, alternando análises discursivas (PÊCHEUX, 1990) e metodologia exploratória voltada à coleta de dados qualitativos, em profundidade e de caráter longitudinal, exatamente porque a situação do objeto sugeriu nossa imersão no campo de trabalho do docente, uma vez que um dos objetivos complementares de pesquisa era familiarizar-se com suas práticas pedagógicas no universo das disciplinas que integram os processos criativos em publicidade. Dessa forma, coube-nos investigar certas concepções às quais se aplicam a intervenção escolar pela ênfase dada aos grandes teóricos da educação. Como recorte do objeto, as análises foram processadas a partir de três dimensões básico-estruturais que interferem no modo de construção e produção de um ambiente adequado para o ensino/aprendizagem, ainda 
pouco explorado na área de publicidade. Optamos, nessa fase da pesquisa, por explorar as condições de ensino em três universidades distintas: a Escola Superior de Propaganda e Marketing de Porto Alegre (ESPM-POA), no Rio Grande do Sul; a Universidade Federal de Pernambuco (UFPE), em Recife; e a Universidade Federal de Santa Maria (UFSM), também do Rio Grande do Sul - que são as unidades de origem dos colaboradores da pesquisa, conforme amostra por conveniência.

As disciplinas da área de criação publicitária foram escolhidas dentre aquelas que constam nas grades curriculares dos cursos, como Criação, Redação Publicitária, e Direção de Arte. A escolha das disciplinas e de suas respectivas turmas foram atreladas à disponibilidade e à autorização da gravação das aulas, primeiramente por parte da direção dos centros e da coordenação dos cursos, depois dos professores responsáveis pelas disciplinas requisitadas e dos estudantes. Para não gerar imprecisão, é prudente que se esclareça como foi realizada a coleta, metodologicamente. Os conteúdos praticados em sala de aula foram gravados, em áudio e vídeo, compreendendo aulas expositivas e, no mínimo, uma atividade prática aplicada em cada disciplina, com seus prováveis momentos: passagem das instruções da atividade prática (trabalho) por parte do professor; orientações individuais ou coletivas do professor aos estudantes; defesa/ apresentação do trabalho por parte dos estudantes aos seus colegas de turma e ao professor.

Quanto à materialidade discursiva utilizada para fins de análise neste artigo, constituímos a montagem do material a partir do registro das produções de professores e estudantes de disciplinas da área de criação publicitária da UFPE e da UFSM, colocando-os em perspectiva em relação aos dados já produzidos no trabalho de campo na ESPM e a um pré-trabalho feito na Universidade de Santa Cruz do Sul (UNISC), do Rio Grande do Sul. Examinamos o processo de ensino e aprendizagem de criação publicitária por meio dos diálogos internos no ambiente de aula, com base nos registros das atividades. Em suma, após assistir e decupar as aulas gravadas, configuramos o "texto na íntegra" do qual foram extraídos os discursos e demais análises situacionais.

Cabe destacar, sobretudo, que trabalhamos sobre um corpus experimental, porque o espaço de aula como local de observação e a aula em si são pautados pela subjetividade. O rumo da aula assumiu, em muitos casos, diversos sentidos no seu desenvolvimento. Em síntese, ao examinarmos o que acontece em sala de aula por intermédio da gravação em áudio e vídeo não nos apegamos às tradicionais entrevistas em profundidade, às observações dos participantes nem aos depoimentos ou relatos. A abordagem metodológica representou um avanço experimental na técnica de coleta no campo educacional, o que oportuniza aplicar novos métodos de investigação. Na medida em que faltam dados sobre a ação educativa em sala de aula, passamos a considerá-la um espaço a ser mais explorado por pesquisadores, tornando-a peça-chave da investigação e do campo empírico. Acreditamos que o fazer do professor em sala de aula deve estar em permanente debate. Por isso nos interessa penetrar nesse espaço “sagrado” não (ou pouco) observado, sem querer espionar o professor, mas procurando auxiliá-lo a refletir sobre suas práticas para aprimorá-las.

Nossas hipóteses preliminares perpassam o entendimento de que a criatividade aplicada à publicidade é uma capacidade híbrida e pluricultural que pode ser estimulada ou favorecida a partir de processos pedagógicos que permitam a liberdade do pensamento, a flexibilização de dinâmicas e exercícios criativos, bem como a oferta de uma estrutura ambiental pertinente às relações de produção criativa nas quais se insere 
o jovem aprendiz-aluno. Mas, ao contrário disso, há uma espécie de estandardização dos procedimentos pedagógicos nas escolas de publicidade, onde o conteúdo, as práticas e os ambientes são homogeneizados e poucos flexíveis quanto à liberdade de processos e de produção.

Como qualquer exploração, a pesquisa exploratória depende da intuição do explorador (neste caso, do pesquisador), de modo que nossa compreensão de pesquisa assume o caráter empírico, uma vez que se utiliza de um experimento (modelo da realidade pesquisada) para testar e validar hipóteses, favorecendo nossos apontamentos e permitindo uma compreensão mais objetiva.

\section{DAS ANÁLISES E OBSERVAÇÕES}

\section{Dimensão interacional}

Quando pensamos o ensino de criação publicitária, com recorte para explorar a necessidade de uma nova perspectiva educativa, tentamos nos pautar em algumas proposições teóricas que são parte do princípio inicial (da estrutura) de nossas pesquisas. Consideramos, portanto, o pressuposto de que houve uma mudança da relação entre professor e aluno e de que, por grande parte da história, a atuação docente seguiu um modelo cartesiano, como o da educação "bancária”, que resiste nos dias de hoje.

O educador faz "depósitos” de conteúdos que devem ser arquivados pelos educandos. Desta maneira a educação se torna um ato de depositar, em que os educandos são os depositários e o educador o depositante. $\mathrm{O}$ educador será tanto melhor educador quanto mais conseguir "depositar” nos educandos. Os educandos, por sua vez, serão tanto melhores educados, quanto mais conseguirem arquivar os depósitos feitos. (FREIRE, 1983, p. 66)

Ancorados na percepção de que o mundo moderno exige uma nova concepção de relação entre professor e aluno, que reflete por consequência um novo método de trabalho, buscamos construir uma projeção do que se espera do professor de publicidade seguindo a visão de Paulo Freire, que, apesar de um tanto quanto utópica, nos traz sóbrios esclarecimentos de que não há quem ensine e não aprenda nem há quem aprenda e não ensine. Freire prova, tão logo, que através da "problematização" da realidade e da significação é possível desenvolver uma concepção libertadora na relação professor e aluno, ou conhecimento e aprendizagem.

Como situação gnosiológica, em que o objeto cognoscível, em lugar de ser o término do ato cognoscente de um sujeito, é mediatizador de sujeitos cognoscentes, educador, de um lado, educandos, de outro, a educação problematizadora coloca, desde logo, a exigência da superação da contradição educador x educando. Sem esta, não é possível a relação dialógica, indispensável à cognoscibilidade dos sujeitos cognoscentes, em torno do mesmo objeto cognoscível. (Ibidem, p. 78)

Tão logo entendida a proposição freiriana, lançamo-nos sobre o desafio de contextualizar o papel do professor publicitário centrado 
no ideal de "libertação dos estudantes". Assumimos de antemão que deveríamos nos permitir, mesmo em caráter experimental, a condição de mediador, ou de nexialista. Ao pensar o professor de criação publicitária entendemos, ainda, que a orientação se configura em uma situação de aprendizagem que, dependendo da condução dada pelo professor, torna a aula participativa e possibilita ao estudante falar bastante ao realizar atividades/exercícios e negociar significados com seus colegas de classe, porque qualquer relação de troca requer ouvir e falar. "O abandono da narrativa implica a busca de maneiras de ensinar, nas quais, metaforicamente, o professor fale menos, narre menos, e o aluno fale mais, participe criticamente de sua aprendizagem” (MOREIRA, 2010, p. 4).

Em episódios educativos observados nas instituições de ensino pesquisadas detectamos sempre alguma forma de diálogo incitada pelo processo de orientação, pois nele o professor não ficava falando sozinho enquanto o aluno apenas ouvia e anotava. Pelo contrário: encontramos professores que deixavam o estudante falar; ouviam mais do que falavam; estimulavam o estudante a procurar caminhos e descobrir respostas. Assim, em vez de oferecer respostas prontas, os docentes empoderam o estudante ao guiá-lo por diversas alternativas durante o processo criativo. Estamos abordando aqui um processo de orientação movido pela curiosidade e igualmente por ser um facilitador de descobertas.

Do que compreendemos sobre as estruturas interacionais lançadas por Piaget (1977), a qualidade do processo cognitivo depende da relação dialógica que se estabelece entre o professor e o aluno, de forma que o conhecimento se desenvolve a partir da qualidade dessa interação mediada pela ação do sujeito com seu objeto.

Coube-nos ressaltar, entre tantos processos, que o modelo de relação visto na UFPE, na disciplina de Redação Publicitária, denota a existência de diferentes momentos interacionais, nos quais é dispensada a crítica na medida em que o professor costuma promover devolutivas mais extensas em meio à apresentação do produto final, gerada nas atividades práticas dos trabalhos discentes, além de abrir terreno para a participação dos estudantes na crítica e na autocrítica a fim de encorajar a troca e o compartilhamento. Nesse caso, em especial, é importante destacar que o enrijecimento burocrático de cumprir a meta de conteúdo é subtraído pela sensibilidade do docente ao valorizar o conflito e o embate de ideais como subsídio essencial do processo criativo.

\section{Dimensão técnica}

Chegamos, então, ao ensino de criação publicitária, em que as práticas pedagógicas tradicionais devem ser consideradas como secundárias e não essenciais. Ao falar de criatividade não podemos reprimir sua amplitude de alcance, referindo-se exclusivamente às práticas produtivas que geram produtos de publicidade; temos que pensar de modo complexo, aberto e interdisciplinar. Edgar Morin (2005) entende que só o pensamento complexo sobre uma realidade também complexa é que pode fazer avançar a reforma do pensamento na direção da contextualização, da articulação e da interdisciplinarização do conhecimento produzido pela humanidade.

Diante do exposto, o ensino de criação publicitária deve adquirir conhecimentos híbridos, conectar-se com práticas que estão fora da publicidade e induzir os sujeitos colocados da condição de aprendiz a experimentar emoções, paixões e desejos que estão inicialmente fora de anúncios, cartazes e filmes publicitários. Para Moran (2000, p. 23), 
aprendemos melhor quando vivenciamos, experimentamos e sentimos. Aprendemos quando relacionamos, estabelecendo vínculos/laços entre o que estava solto, caótico, disperso, integrando-o em um novo contexto, dando-lhe significado, encontrando um novo sentido. Como complemento, Paulo Freire (1983) ainda diz que como professores não devemos esperar que os estudantes articulem todo o conhecimento. É tarefa do professor assumir iniciativa e dar exemplo de como fazê-lo.

Nesse ponto, há de se destacar a necessidade de integrar conhecimentos da filosofia, das artes e das sociologias com outras categorias técnicas do ensino publicitário. Mas o que observamos muitas vezes é que essas disciplinas ficam isoladas e pouco integradas às competências de caráter mais aplicado, indissociáveis do exercício da profissão. O ensino da criação publicitária, ao menos nas análises preliminares, permanece quase que imutável nas suas práticas pedagógicas, como um objeto institucionalizado.

a institucionalização é considerada como um "processo fenomenológico por meio do qual certas relações e ações sociais começam a ser consideradas como dadas” e uma situação na qual cognições partilhadas definem "o que tem sentido e quais ações são possíveis". (ZUCKER apud POWELL; DIMAGGIO, 1990, p. 9, tradução minha)

Se nos dedicarmos, de maneira mais específica, a um recorte de quarenta anos, roteirizado por planos de aula homogêneos e pouco produtivos, no que permite ao professor ousar com novas experiências sensoriais e atitudes lúdicas de engajamento o ensino de criação publicitária está subjugado a um tipo de convenção que assume o status de regra.

O histórico das atividades criativas vistas nos cursos de publicidade revela muito pouco quanto à existência de novos exercícios criativos capazes de estimular uma produção acadêmica baseada na troca de conhecimento pelas relações humanas de trabalho. Podemos ousar dizer que, em linhas gerais, se resumem à confecção de peças gráficas (revista, jornal, outdoor), ao desenvolvimento de produtos eletrônicos (comerciais de rádio, TV e roteirização) e ao desenvolvimento de campanhas publicitárias sobre problemas fundamentais de comunicação mercadológica.

Atividades artísticas ligadas ao desenho, às artes plásticas e a outros produtos da expressão humana - conteúdos culturais-filosóficos - são poucos vistos. Do mesmo modo, não estimulamos os alunos a refletirem sobre a condição moderna do homem, do amor, da morte, da ambição, dos dogmas, do ciúme, da inveja, do poder, da tolerância e da democracia. Nossas escolas, esmagadas pelo tensionamento do mundo competitivo tecnológico, pouco consegue acompanhar o ritmo das transformações culturais.

Os resultados decorrentes do derretimento do conceito de publicidade, passando à concepção de hiperpublicidade, já revisitados por diferentes autores, somam-se a outros dois contornos convergentes da política de educação brasileira. De um lado, a compressão das verbas destinadas à pesquisa e à iniciação científica, fundamentais para o fomento do conhecimento produzido nas escolas públicas; do outro lado, o baixo rendimento dos salários praticados na iniciativa privada, resultado dos grandes conglomerados do capital estrangeiro que inibem a qualificação e o avanço de uma classe profissional estimulada/ valorizada. Torna-se cada vez mais difícil contemporizar os desafios 
da sala de aula em um mundo multiconectado, interdisciplinarizado, economicamente globalizado e complexo.

No entanto, em diferentes aspectos foi possível identificar uma espécie de intencionalidade criativa de maior nível em atividades interdisciplinares praticadas na ESPM e na UFSM, onde a convergência de conhecimento ainda está restrita ao campo da publicidade, não conseguindo escapar para outros centros de conhecimento. Parece que na UFSM há uma tensão maior para se alcançar a condição multi e interdisciplinar da produção criativa em suas respectivas cadeiras, havendo uma espécie de pré-disposição colaborativa, vista em exercícios e na integração com diferentes disciplinas. No entanto as práticas, de modo geral, ainda são muito parecidas nas três instituições observadas.

\section{Dimensão do meio}

Entre tantas contribuições que Vygotsky promoveu quanto ao desenvolvimento infantil e à sua relação com a aprendizagem em meio social, coube-nos, nesta ocasião, uma referência estendida para o contexto do ensino superior do estudante na sua fase de desenvolvimento intelectual enquanto adulto. Tentando seguir pelo mesmo viés das proposições teóricas de Vygotsky (1989), buscou-se olhar, sobretudo, para a questão do ambiente do ensino de criação publicitária, ou seja, o espaço em que se projeta o indivíduo, o meio em se que vive.

Por centramos nosso olhar no ensino superior, há de se considerar a distinção de meio quando se trata de espaços públicos e privados, da mesma forma que existem dois perfis de estudante, na medida em que nos referimos a essas instituições e a seus modelos de seleção, embora essa dicotomia não seja absoluta ou determinista.

Junto dos dispositivos jurídicos/econômicos, leva-se em consideração o planejamento do trabalho de aula bem como a adoção de plataformas que são usadas para assegurar que o estudante alcance os objetivos propostos inicialmente em seus projetos. As metodologias mais adequadas para o desenvolvimento da aprendizagem em uma turma também podem variar em função dos diferentes perfis que a constituem (na sua diversidade ou homogeneidade). $\mathrm{O}$ reconhecimento dessas especificidades, relativas ao perfil das turmas, no seu contexto ambiental, pode variar quanto às necessidades de aprendizagem profissional. Assim, é importante para os professores uma análise atenta ao padrão de comportamento de cada turma, não só na escolha do tipo de procedimento didático a ser perseguido.

Na ESPM, por exemplo, existiram casos em que o professor assumiu em seu discurso para os estudantes que, por considerá-los aptos a estudarem em uma escola de referência na área de negócios e, da mesma forma, por esta preservar fortes vínculos com o ambiente profissional, eles seriam cobrados e exigidos no seu processo de formação instrucional com tal rigor. Como reflexo desse modelo de discursivo, acreditamos que as imagens que os docentes e discentes elaboram na sua ambiência instrucional dinamizam um tipo de imaginário problemático sobre a publicidade, muitas vezes ligado a um sistema dinâmico do campo dos negócios e com pouco vínculo afetivo para concepções de conteúdos mais criativos e humanísticos.

Poderíamos acrescentar, de imediato, que a maneira imaginada pelo professor para se sentir pertencente e incorporar-se a filosofia da 
instituição é abranger no discurso pedagógico o discurso do mercado publicitário que, por sua vez, reverbera um mecanismo fundamental, integrador do sistema social e da organização da ação.

Esse tipo de institucionalização é consequência de processos pelos quais atores, em conformidade com os sistemas de valores de uma sociedade e temendo as consequências decorrentes do desvio, internalizam rumos de ação prescritos ou esperados como sendo apropriados ou certos. (PECI; VIEIRA; CLEGG, 2006, p. 54)

A dicotomia entre ambientes públicos e privados não é mérito desta pesquisa, mas devemos olhar para esses dois gêneros de instituição no sentido de tentar compreender sob quais condições estruturais se define cada meio, buscando saber qual deles é mais ou menos favorável para a aquisição de conhecimentos e para a interação do sujeito com o respectivo meio. Vygotsky enfatiza ainda que o material simbólico presente em nossos estudos pode ser visto sob a perspectiva do gênero das atividades que lhe são atribuídas. Como ponto de partida pensávamos, como hipótese, que as escolas privadas, por terem um modelo de gestão diferente das públicas e também pelo perfil do aluno que lá ingressa, definiriam resultados que sugerissem práticas interacionais e simbólicas em perspectivas diferentes ou antagônicas. Outra suposição que nos rondava partia da sensação de que em escolas privadas o número de alunos em cada turma seria superior e mais heterogêneo do que em escolas públicas. Como condição, esse fator interferiria diretamente no processo interacional do professor com seus alunos. Porém, aparentemente, essa hipótese não se confirmou.

Mediante amostra analisada, essa pré-condição não se mostrou uma máxima, visto que as turmas na UFPE eram maiores que as turmas da ESPM. Ainda assim, independentemente do número global de cada turma e mesmo com uma porcentagem reduzida de alunos, na Universidade Federal de Santa Maria em algumas dinâmicas de aula formaram-se grupos de até cinco alunos. Nesse contexto, as produções de conhecimento favorecidas a partir de relações intra e interpessoais e de troca com o meio, mesmo com perfis de escolas distintas, mantiveram-se lineares e próximas quanto à qualidade do processo denominado de mediação.

$\mathrm{Na}$ perspectiva da tecnologia, esses ambientes modificam-se em elementos conectores em função do tempo para desenvolvimento das atividades e do espaço físico adequado para realizá-las. Ou seja, em se tratando da quantidade e da qualidade de recursos pedagógicos que o professor tem a sua disposição, é possível ampliar o espaço/tempo interacional entre alunos e docentes. Na UFPE o meio físico interferiu na qualidade dos processos, de modo que a prática, em caráter presencial, sofreu fortes desestímulos dos resultados desse meio. Nessa condição, as qualidades simbólicas das atividades reduziram o nível de expectativa do aluno quanto ao desafio que lhe era lançado. $O$ espaço apertado, com mesas pequenas e uma área de projeção de imagens com baixa definição, diminuíram o nível interacional dos alunos.

De modo geral, atividades simbólicas puderam ser auferidas em decorrência do tamanho do desafio que sugerem e, do mesmo modo, das condições de ambiente que estimulam o aluno a superar esse desafio; ou seja, o meio e o simbolismo são estruturas intrínsecas à qualidade da produção criativa e não podem ser julgados de forma isolada. 
Nível médio: o diálogo se efetiva de modo intenso nos pequenos grupos (de dois a três estudantes), tornando-se uma relação conjunta do professor e do grupo de alunos no ato comum do conhecimento. Os exercícios raramente são individuais, o que reforça o caráter interacional entre os

ESPM estudantes; nos pequenos grupos há interação em maior nível, contribuindo ainda mais para o conhecimento. 0 que pode ser considerado baixo é o fato de os trabalhos/ atividades no decorrer do semestre raramente serem apresentados e compartilhados com a turma toda (esfera centrada no professor).

Nível alto: o professor a todo momento interpela os alunos projeta problemas, incitando discussões e debates reflexivos que permitem a exposição de inúmeras possibilidades ideativas. Em várias situações é permitido o diálogo e a contraposição de críticas que se concretizam com primor,

UFPE haja vista que o professor costuma dar devolutivas mais extensas em meio à apresentação do produto final de cada trabalho, além de abrir terreno para a participação dos estudantes na crítica e autocrítica, a fim de encorajar a troca e o compartilhamento.

Nível baixo: sobre a formação de equipes até cinco alunos, mesmo entendendo que em certas ocasiões esse tipo de desenho pode ser pertinente em face da complexidade dos desafios criativos, constatamos que em determinados momentos essa postura, além de sobrecarregar alguns

UFSM membros da equipe, dificultava a interação do docente com o processo de aprendizagem. No entanto, em trabalhos mais simples, quando a situação pedia a criação de roteiros para peças publicitárias de rádio e de televisão, nas disciplinas de Redação Audiovisual e de Redação para Rádio, os docentes optaram por trabalhar em formato de duplas, criando outra dimensão dialógica, sem exclusão de estudantes.

Fonte: Elaborado pelo autor, 2018.
Nível médio: os trabalhos criados são apresentados oralmente apenas eventualmente. Por extensão, o compartilhamento com a turma dos resultados e das avaliações ocorre apenas quando os trabalhos propostos são mais complexos e extensos, fazendo parte de um episódio isolado. No momento das atividades em grupo são geradas, inclusive, propostas que envolvem mais de um disciplina - projetos interdisciplinares. Logo as proposições interdisciplinares favorecem o cruzamento de conhecimento e estimulam a produção colaborativa.

Nível médio: o professor optou por não seguir o programa oficial da disciplina, adaptando o conteúdo ao seu método de trabalho. Mesmo assim, o professor oferece diversas possibilidades de aplicação prática (uma gama de exercícios com problematizações distintas) e oferece muitos suportes de trabalho (computadores, internet, projetor, sistema de áudio e softwares de edição)

Em alguns momentos da disciplina utilizou as mídias digitais (Facebook) como ferramenta de compartilhamento, submissão de arquivos e canal de resposta para as orientações, embora de forma desproporcional.

Nível alto: os professores são proativos, criam estratégias pedagógicas em níveis distintos, com a proposta de exercícios que vão dos mais simples aos mais complexos: criação de roteiros, produção de spot para rádios e desenvolvimento de campanhas publicitárias e outros textos.

Em certas ocasiões o professor organizou um sistema de compartilhamento de arquivos através do qual prestava orientação on-line para a confecção de roteiros. Em redação audiovisual o professor organizava orientações coletivas e todos os alunos podiam opinar em todos os trabalhos, o que gerava discussões interessantes e uma descentralização do papel docente.
Nível médio: as turmas apresentam uma configuracão razoável em relação ao número de alunos que desenvolvem os trabalhos de criação publicitária. Essa condição permite a formação de pequenos grupos - compostos por dois ou três estudantes - com suportes adequados.

Os laboratórios não possuem distinção de qualidade em relação às escolas públicas, visto que existem limitações técnicas em diferentes níveis, algo muito similar às outras instituições analisadas. A tradição da ESPM como uma escola integrada ao mercado também gera uma condição simbólica que merece destaque.

Nível baixo: embora tenha trabalhado com o conceito de duplas (criativas), as aulas aconteceram de forma improvisada nos espaços da agência experimental. O professor encontrou, em alguns momentos, dificuldades para interagir com a turma, considerando que as dimensões do espaço favoreciam a dispersão e um baixo rendimento da produção in loco. Em alguns momentos as aulas tiveram que ser interrompidas porque alunos dispersos deixavam de colaborar no processo de discussão pedagógica e desvirtuavam a atenção de outros estudantes mais interessados.

Nível médio: em agência experimental os grupos não possuíam a obrigação de permanecer no ambiente de sala de aula o tempo todo. A criação poderia ser feita no jardim da universidade, nos corredores, na sala do diretório acadêmico etc. Os professores iam até o local em que os grupos estivessem. $\mathrm{O}$ isolamento dos grupos e sua alocação em lugares que Ihes pareciam mais cômodos permitiram um ambiente mais frutífero, já que mais silencioso e calmo. Assim as conversas entre docentes e discentes eram mais demoradas e sem a preocupação com interrupções ou ruídos de outros estudantes. A organicidade do processo aumentou a ludicidade do ambiente e horizontalizou o protagonismo do professor com o dos estudantes. 


\section{ASPECTOS FINAIS}

Ao analisar o ensino de criação publicitária, partimos do pressuposto teórico de que nossos trabalhos deveriam se ater, inicialmente, a alguns aspectos metodológicos que nos permitissem, a partir da pesquisa experimental, adotar uma lógica interpretativa com parâmetros sólidos e que de antemão já estivessem dentro de um campo referencial. Por isso optamos por atuar com essas três dimensões, visto que acreditamos ser esta uma área segura para o tipo de apontamentos que intencionamos fazer. Dessa forma, as dinâmicas interacionais são estabelecidas na condição em que o professor se projeta: ao invés de protagonista do discurso, ele assume a categoria de coadjuvante, no sentido de que seus alunos conquistem confiança para assumir seu protagonismo, tomando para si a responsabilidade das falas e das ideias.

Como mediador no processo de ensino, o docente supera o modelo tradicional e se lança numa nova postura, agora como nexialista, interligando múltiplos discursos. Nas projeções de Piaget e de Paulo Freire essa é uma questão fundamental para a superação do paradigma clássico e para o lançamento de novas ideias. Em relação à segunda dimensão, na qual relacionamos as condições técnicas, principalmente no que diz respeito às estratégias pedagógicas, coube nosso olhar mais crítico para a questão do processo de interdisciplinaridade, também amplamente discutido em diversas flexões de Edgar Morin. Nesse contexto, ficam três perguntas que precisam ser levadas adiante em nossos estudos: como essa interdisciplinaridade está sendo desenvolvida e, sobretudo, pensada nas escolas e nas disciplinas de criação publicitária? Quais são as condições a que esses cursos atendem? Quais são os objetivos principais que se dispõem a cumprir?

Busca-se com esta pesquisa, além de compreender o discurso pedagógico de criação publicitária, o entendimento de quais são as condições em que a interdisciplinaridade pode ser desenvolvida. Percebemos ainda que na ESPM, assim como na UFSM, são desenvolvidos processos interdisciplinares, e muitos deles acontecem de forma sistemática e bem induzida.

No que se refere à terceira dimensão estudada - orientada pelo pensamento de Lev Vygotsky e por sua relação com o impacto que o meio exerce no ambiente de aprendizagem, sobretudo no modelo apresentado pelas escolas de publicidade -, direcionamos nosso olhar para a sala de aula. Acredita-se que a revolução na educação do ensino superior inicia-se nas suas dimensões espaciais e na sua relação com o mundo. No entanto, o que percebemos é que estamos enraizados nas relações baseadas na institucionalização dos ambientes - modelo secular, com pouco espaço para o pensamento criativo, para a expressão artística, para a brincadeira, para o lúdico. O modelo clássico, como o conhecemos, talvez seja um dos principais elementos que transformaram em estérea a capacidade elaborativa da criatividade em sala de aula. Pensar em quais ambientes seriam interessantes para ensino (saraus literários, oficinas de criação, laboratórios de criação, oficinas literárias, oficinas de escrita criativa, estúdios de arte, ateliês) nos motiva a avançar com as pesquisas.

A arquitetura, assim como o contexto simbólico em que se inserem as atividades (sejam de alta ou baixa complexidade), são variáveis imprescindíveis para o desenvolvimento de uma nova condição de ensino. Diante do exposto, questionamos quais seriam os ambientes especiais voltados para as práticas criativas? Como gerar produção criativa diferenciada que não seja exclusivamente a produção de um anúncio ou 
de uma peça? Como os alunos estão participando de um entrecruzamento de práticas criativas que se completam com as práticas publicitárias?

Na UFPE, por exemplo, as práticas criativas acontecem no ambiente clássico de sala de aula, que faz parte de um modelo centenário na educação brasileira, e esse tipo de composição do meio inibe qualquer tipo de produção criativa. Dessa forma, temos que projetar como gerar novos ambientes que sejam híbridos na sua configuração de produção. Nesse sentido, nosso estudo traz algumas contribuições que apontam para quais direções o ensino de criação publicitária deve olhar. Ao contrário do que se observa, deveriam haver outras configurações de sala de aula/ disposição das classes, intervenções nas paredes, espaços lúdicos, quadros e textos inspiradores/motivadores.

As instituições ainda ensinam utilizando apenas interações em sala de aula e em laboratórios técnicos. Em vez de espaços institucionalizados com mesas e carteiras, poderíamos priorizar um espaço aberto, com arquitetura mais inteligente e ambiência projetadas para ações externas às paredes ou às salas de aula - uma variedade de espaços para potencializar o aprendizado.

Portanto pensamos que essas três dimensões elencadas podem servir como ponto de partida para que professores da área criação publicitária comecem a desenvolver novas reflexões sobre o discurso criativo, no sentido de elaborar uma pedagogia que nos auxilie no processo de educação. Sabemos também que deve haver outras dimensões igualmente importantes dentro de determinados contextos e, como proposta inicial, formamos um grande espaço de pouso onde é possível pairar com outras contribuições que sejam alinhadas para integrar novos resultados.

\section{REFERÊNCIAS}

BERGER, P. L.; LUCKMANN, T. A construção social da realidade. 20. ed. Petrópolis: Vozes, 2001.

CORREA, R. S. Tecnologia, desafios e avanços no ensino da Publicidade. Conferência apresentada no IV Colóquio de Graduação em Publicidade: Interdisciplinaridade, Empreendedorismo e Tecnologia, Rio de Janeiro, 2016.

COVALESKI. R. Publicidade híbrida. Curitiba: Maxi, 2010.

FREIRE, P. Pedagogia da autonomia. Saberes necessários à prática educativa. São Paulo: Paz e Terra, 1997.

Pedagogia do oprimido. Rio de Janeiro: Paz e Terra, 1983.

HANSEN, F. As formações imaginárias e seus efeitos de sentido no ensino e na aprendizagem de criação publicitária. Educação e Pesquisa, São Paulo, v. 39, n. 2, p. 465-476, abr./jun. 2013.

MORAN, J. M. Ensino e aprendizagem inovadores com tecnologias audiovisuais e telemáticas. In: MORAN, J. M.; MASETTO, M. T.; BEHRENS, M. A. (Orgs.). Novas tecnologias e mediação pedagógica. Campinas: Papirus, 2000.

MOREIRA, M. A. Abandono da narrativa, ensino centrado no aluno e aprender a aprender criticamente. In: VI ENCONTRO INTERNACIONAL, 6., ENCONTRO NACIONAL DE APRENDIZAGEM SIGNIFICATIVA, 3., 2010, São Paulo. Anais... São Paulo: EIAS, ENAS, 2010. p. 1-12. Disponível em: http://moreira.if.ufrgs.br/Abandonoport.pdf. Acesso em: 20 jun. 2017. p. 1-12.

MORIN, E. Educação e complexidade, os sete saberes e outros ensaios. São Paulo: Cortez, 2005.

A cabeça bem-feita: repensar a reforma, reformar o pensamento. Rio de Janeiro: Bertrand do Brasil, 2001.

PECI, A.; VIEIRA, M. M. F.; CLEGG, S. R. A construção do "Real" e práticas discursivas: o poder nos processos de institucionaliz(ação). Revista de Administração Contemporânea, Curitiba, v. 10, n. 3, p. 51-71, 2006. 
PIAGET, J. O desenvo/vimento do pensamento: equilibração das estruturas cognitivas. Lisboa: Dom Quixote, 1977.

PIAGET, J.; INHELDER, B. A psicologia da criança. São Paulo: Difel, 1986.

POWELL, W. W.; DIMAGGIO, P. J. (Eds.). The new institutionalism in organizational analysis. Chicago: University of Chicago Press, 1990.

VYGOTSKY, L. S. A formação social da mente. 2. ed. São Paulo: Martins Fontes, 1989.

TAVARES; D. Ensino da eficácia publicitária: conectores isotópicos. In: CONGRESSO BRASILEIRO DE CIÊNCIAS DA COMUNICACCÃO, 35., 2012, Fortaleza. Anais... Fortaleza: Intercom, 2012. Disponível em: <https://bit.ly/2IGNHK8>. Acesso em: 29 jun. 2018. p. 1-15. 